\title{
Begravede dale i Århus Amt - undersøgelse af Frijsenborg-Foldby-plateauet
}

Af Jette Sørensen, Rambøll (tidl. ansat i Sedimentsamarbejdet); Verner Søndergaard, Århus Amt; Christian Kronborg, Geologisk Institut, Aarhus Universitet; Ole Bjørslev Nielsen, Geologisk Institut, Aarhus Universitet og Richard Thomsen, Århus Amt

I den foregående artikel kiggede vi på to af de metoder, der er benyttet i forbindelse med kortlægning af grundvandsressourcerne i Århus Amt. Der så vi, hvordan der i Århus Nord og ved Hadsten ved hjælp af geofysiske metoder er blevet identificeret et imponerende netværk af begravede dale, og vi sluttede af med at omtale, hvordan disse dales indfyldning på baggrund af fingrusanalyser er blevet henført til forskellige glaciationer.

I denne artikel redegøres nærmere for, hvordan de enkelte undersøgelsesmetoder i kombination har kunnet medvirke til at opnå en rigtigt god forståelse af geologien i et område og til kortlægning af grundvandsmagasinerne. Dette illustreres ved FrijsenborgFoldby-plateauet, og nogle af de begravede dale, der gennemskærer det.

En morfologisk beskrivelse af plateauet Frijsenborg-Foldby-plateauet ligger på alle sider omgivet af større begravede dale, hvis bredde varierer mellem 0,9 og $2,5 \mathrm{~km}$ (se figuren s.16 i forrige artikel). Mod øst og

Oversigt over fingrusfordelingen $i$ tillenheder fra Århus-området . Efter Kronborg et al. (1990). /2/. (Grafik: Jette Sørensen)

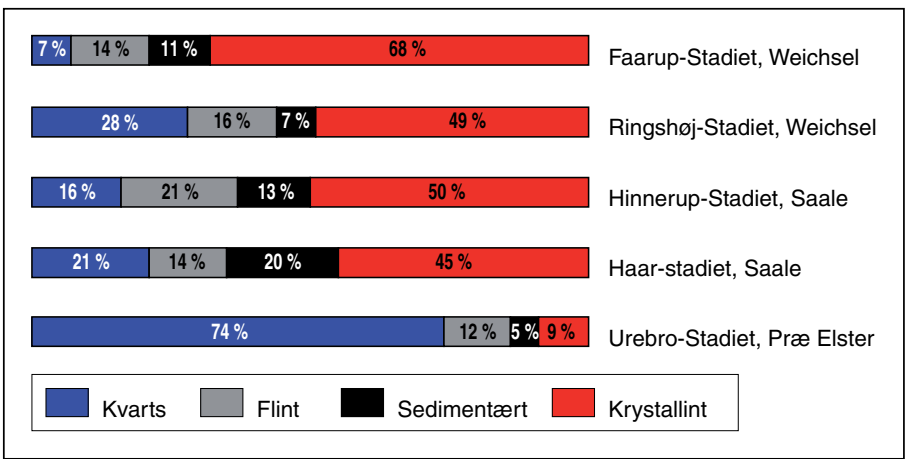

sydøst ses Ristrup-Grundfør-Ødum-dalen, mod nordøst og nord ses Haar-Trige-Elsteddalen og mod vest og sydvest ses den begravede dal, der forløber fra Voldby i syd, vest om Hammel, videre nordpå mod Thorsø og op mod Ulstrup i Viborg Amt.

Plateauet, hvis overflade er beliggende mellem kote +10 og +75 m DNN, består af prækvartære aflejringer, der overlejres af et kvartært dække med en begrænset tykkelse på mellem 5 og $35 \mathrm{~m}$. Fra den eneste af de dybe undersøgelsesboringer (DGU nr. 78.863), som er placeret på det prækvartære plateau, ved man, at de øvre prækvartære aflejringer af glimmerler kan korreleres til Vejle Fjord-Formationen, der er afsat i Nedre Miocæn. Herunder ses Brejning Ler, Branden Ler, Linde Ler og Viborg Ler fra Oligocæn, og fra ca. kote $+2 \mathrm{~m} \mathrm{DNN}$ træffes Søvind Mergel og Lillebælt Ler fra Eocæn $/ 1$. En oversigt over den prækvartære lagserie i boring $78.863 \mathrm{kan}$ ses i figuren på s.20. Foruden at give information om den tertiære lagserie, de begravede dale er skåret ned i, har boring 78.863 også kunnet bruges til at give et bud på, hvilke lag i den tertiære lagsøjle der resulterer i den gode elektriske leder i TEM-tolkningerne. Der er udført såvel gammalogs som elektriske logs i det åbne borehul. Ved den aktuelle boring svarer koten for den gode leder til toppen af tertiært ler fra Vejle Fjord-Formationen.

\section{Snegleboringer}

Foruden den dybe undersøgelsesboring er der også udført en række korte snegleboringer på det prækvartære plateau. Disse boringer har haft til formål at verificere TEM-målingernes bestemmelse af den tertiære leroverflades beliggenhed samt at belyse udbredelsen af tynde sandlag, som vil kunne lede vand fra plateauet til grundvandsmagasinerne i de begravede dale. Bortset fra to af de korte boringer, der er udført i mindre lavninger på plateauet, viser disse snegleboringer, at den prækvartære 


\section{Dybe undersøgelsesboringer}

\begin{tabular}{|l|l|l|}
\hline \multirow{2}{*}{$\begin{array}{l}\text { Frijsenborg-Foldby- } \\
\text { plateauet. } \\
\text { Dybe boringer }\end{array}$} & Frijsenborg-Foldby-dalen & $78.862,78.868,78.910$ og 78.1023 \\
\cline { 2 - 3 } & $\begin{array}{l}\text { Lille Frijsenborg-dalen } \\
\text { de begravede dale }\end{array}$ & 78.909 og 78.910 \\
\cline { 2 - 3 } & $\begin{array}{l}\text { Krydspunktet mellem Frij- } \\
\text { senborg-Foldby-dalen og } \\
\text { Lille Frijsenborg-dalen }\end{array}$ & 78.910 \\
\hline
\end{tabular}

Århus Amt har forskellige boringer (i det følgende nævnt ved deres DGU nr.) i området. En oversigt over placeringen af disse boringer, samt øvrige dybe boringer, der er udført i Århus Nord- og Hadstenområdet kan ses i figuren til højre, en del af prøvernes placering er nærmere beskrevet i tabellen ovenfor.

Fra boringerne $78.862,78.863,78.868$ er der undersøgt i alt 49 prøver, mens der fra boringerne 78.909 og 78.910 er udtaget enkelte stikprøver. Der er endvidere undersøgt i alt 119 prøver fra de øvrige dybe undersøgelsesboringer i Århus Nord (78.870, 79.1283, $79.1281,79.1282$ og 79.1319) /1/, mens boringerne fra Hadstenområdet $(78.1017,78.1023,78.1102,78.1027,78.1024,79.1404$, 79.1405 og 79.1402) endnu ikke er undersøgt. På de fleste af de undersøgte prøver er der foruden andre analyser udført fingrusanalyser. Netop fingrusfordelingen er, som det illustreres i teksten, meget vigtig ved korrelation af områdets kvartærstratigrafi.

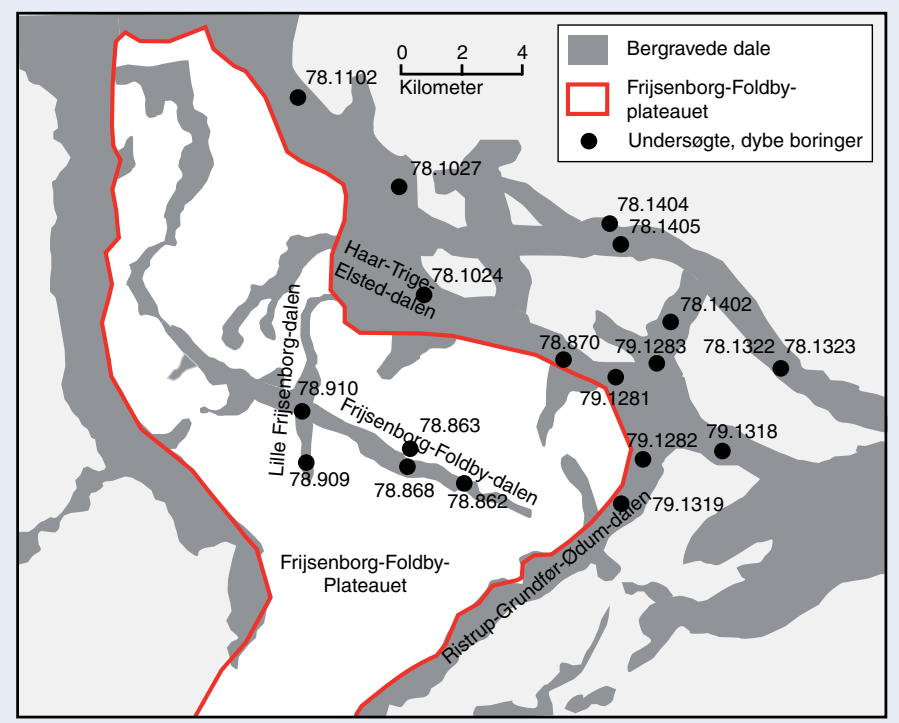

Kortet viser prøvernes placering i området. (Grafik: Jette Sørensen og UVH) overflade er beliggende blot 8-16 m under terræn, og at den udgøres af aflejringer fra Vejle Fjord-Formationen.

\section{Begravede dale}

Frijsenborg-Foldby-plateauet gennemskæres af en række smalle, men forholdsvis dybe og helt begravede dale. Den mest markante af disse dale er Frijsenborg-Foldby-dalen, der fra plateauets sydøstlige rand strækker sig mod nordvest, indtil den på plateauets nordligste del slår et knæk og her i stedet får en nordlig til nordøstlig orientering op mod plateauets nordligste rand.

I den foregående artikel blev det omtalt, at denne ganske smalle, begravede Frijsenborg-Foldby-dal bl.a. er bemærkelsesværdig ved at have et forløb langs det prækvartære plateaus højderyg, hvilket man kan overbevise sig om ved at se på figuren $\mathrm{s} .16 \mathrm{i}$ forrige artikel. Dette må betyde, at den forløber dér, hvor den prækvartære overflade har været udsat for mindst erosion under de efterfølgende glaciationer. Plateauet hælder bort fra Frijsenborg-Foldby-dalen til begge sider ud mod de bredere begravede dale, der omgiver det. Flere steder er disse dale så brede, at der på deres flanker ses en form for terrasser, der måske repræsenterer tidligere erosionsniveauer. De smeltevandssedimenter, der udfylder disse terrasser repræsenterer flere steder i området vigtige, men også overfladenære og dermed sårbare magasiner. I disse år placeres nye vandforsyningsboringer derfor primært centralt i de begravede dale.

Frijsenborg-Foldby-dalens bredde veksler mellem 400 og 1.000 m, og dybden reg- net fra terræn varierer mellem knap $100 \mathrm{~m} \mathrm{i}$ den østlige ende, $160 \mathrm{~m}$ ved Frijsenborg og $205 \mathrm{~m}$ ved Houlbjerg. Bunden er beliggende omkring kote $-20 \mathrm{~m}$ DNN ved Foldby, kote $-75 \mathrm{~m} \mathrm{DNN}$ ved Frijsenborg og i kote -120 m DNN længst mod nordvest ved Houlbjerg. Frijsenborg-Foldby-dalen har således overordnet set en faldende bundkote fra øst mod vest og nordvest, og i den sydøstligste del af dalen er den nedskåret i L5 i Lillebælt Ler-Formation, mens den i den nordligste del er skåret ned til og muligvis ned i den faststående kalk, der her ligger forholdsvis højt. Hældningen på dalens sider er stedvis op til 15 grader, hvilket er særdeles stejlt. Vurderingen af dalflankens hældning er foretaget på baggrund af simple trekantsbetragtninger, dvs. under antagelse af at dalen er V-formet, men da dette ikke er tilfældet, vil flankens egentlige hældning være endnu stejlere! Dalens længde regnet fra øst for Foldby til dens forbindelse til den brede dal nordvest for Houlbjerg er ca. $26 \mathrm{~km}$.

Frijsenborg-Foldby-dalen skæres af flere mindre dale fra en nordøstlig og nordlig retning (se figuren s. 16 i foregående artikel). Én af disse er Lille Frijsenborg-dalen, der har en sydlig til nordlig orientering, er ca. $6 \mathrm{~km}$ lang og mellem 250 og $500 \mathrm{~m}$ bred. Dens bund er beliggende mellem kote -60 og -20 m DNN, og den er således ikke helt så dyb som Frijsenborg-Foldby-dalen. Bunden af dalen hælder fra begge sider ind mod Frijsenborg-Foldby-dalen, og stedvis er hældningen af flankerne i den lille dal af samme størrelse som i denne dal, dvs. omkring 15 grader.

\section{Fingrusanalyser}

Fra området ved Århus Nord er der gennem tiden i specialeafhandlinger og råstofundersøgelser beskrevet en lang række daglokaliteter og boringer. Mange af disse undersøgelser er sammenfattet i Kronborg et al. (1990) /2/, der på baggrund af kinetostratigrafiske analyser (bestemmelse af retningsdata), dateringer og fingrusanalyser opstiller en glacialstratigrafi for området, der bl.a. omfatter tillaflejringer fra 5 forskellige isfremstød (figuren på foregående side) .

Betragtes fingrusfordelingen i tillenhederne i figuren på foregående side, er det tydeligt, at der kan udskilles 3 typer af fordelinger. Nederst ses den meget kvartsrige Urebro Till, der tolkes som værende afsat i et Præ Elster-fremstød, formodentlig Menap. Herover følger tre moderat kvartsholdige tillenheder fra Saale og Tidlig Mellem Weichsel, der ikke umiddelbart kan skelnes fra hinanden på baggrund af fingrusanalyserne. Endeligt ses øverst i stratigrafien en tillenhed fra Sen Weichsel, der med sit meget lave kvartsindhold og høje krystalline indhold let kan adskilles fra de underliggende enheder.

\section{Vidste du:}

At du kan købe alle de tidligere, ikke-udsolgte numre (p.t. 64 stk.) for kun $300 \mathrm{kr}$. (ekskl. porto $63,00 \mathrm{kr}$.)? 
Ved udgangen af 2005 var der i Sedimentsamarbejdet undersøgt $i$ alt 3.100 prøver fra ca. 164 boringer, og erfaringerne fra dette arbejde har vist, at smeltevandsaflejringerne almindeligvis har samme fingrusfordeling som tillaflejringer afsat $i$ forbindelse med det samme fremstød. Tillstratigrafien er derfor også udvidet til smeltevandssedimenter, hvilket især er vigtigt ved korrelation af grundvandsmagasiner mellem forskellige boringer i et område.

\section{Tolkning af sedimentanalyser}

De sedimenter i de enkelte boringer fra Århus Nord, der har samme petrografiske, mineralogiske og stratigrafiske egenskaber, er blevet korreleret, og der er på den baggrund opstillet 3 grundlæggende grupper af sedimenter. Den ældste gruppe, der kun ses i Frijsenborg-Foldby-dalen, har et meget højt kvartsindhold på $81 \%$ og tolkes til at kunne korrelere til de tilsvarende kvartsrige sedimenter, der i glacialstratigrafien for Århus,er henført til et Præ Elster-isfremstød.

Herover følger en gruppe af smeltevandssedimenter og tillaflejringer, der med et moderat indhold af kvarts på mellem 14 og $27 \%$, tolkes til at korrelere til den store gruppe af sedimenter i områdets glacialstratigrafi, der menes at være afsat i Saale eller Tidlig Mellem Weichsel. Disse sedimenter udfylder det meste af Ristrup-GrundførØdum-dalen og Haar-Trige-Elsted-dalen, der omkranser Frijsenborg-Foldby-plateauet, mens de kun ses i toppen af Frijsenborg-Foldby-dalen og den krydsende Lille Frijsenborg-dal. Endeligt ses der øverst i dalfyldet $i$ alle fire dale enheder af moræneler, der med et meget lavt kvartsindhold på gennemsnitligt $7 \%$ og et højt krystallint indhold på gennemsnitligt $71 \%$, kan korreleres til NØ-isen og eventuelt Ungbalten i Sen Weichsel.

\section{Dalindfyldningernes alder}

For at illustrere dalindfyldningernes alder og indbyrdes relationer er der udarbejdet to geologiske snit. På figuren til højre ses et geologisk snit på tværs af Frijsenborg-Foldby-dalen. Man kan her se, hvordan dalen er skåret dybt ned i de neogene og palæogene aflejringer. Fingrussammensætningen er angivet med barrer, og det fremgår, at der er stor petrografisk forskel på de kvartære sedimenter, idet det meste af dalfyldet udgøres af de stærkt kvartsholdige Præ Elster-smeltevandssedimenter, mens de overliggende moræne- og smeltevandsaflejringer med et moderat kvartsindhold er henført til ét af fremstødene i Saale eller Tidlig Mellem Weichsel. Øverst ses den meget kvartsfattige till, der tolkes afsat under $\mathrm{N} \varnothing$ fremstødet i Sen Weichsel.

I figuren på næste side ses et geologisk snit på langs med Frijsenborg-Foldby-dalens midte. Det ses her, hvordan Lille Frijsenborg-dalen er eroderet ned i de kvartsrige Præ Elster-aflejringer, der udfylder Frijsen-

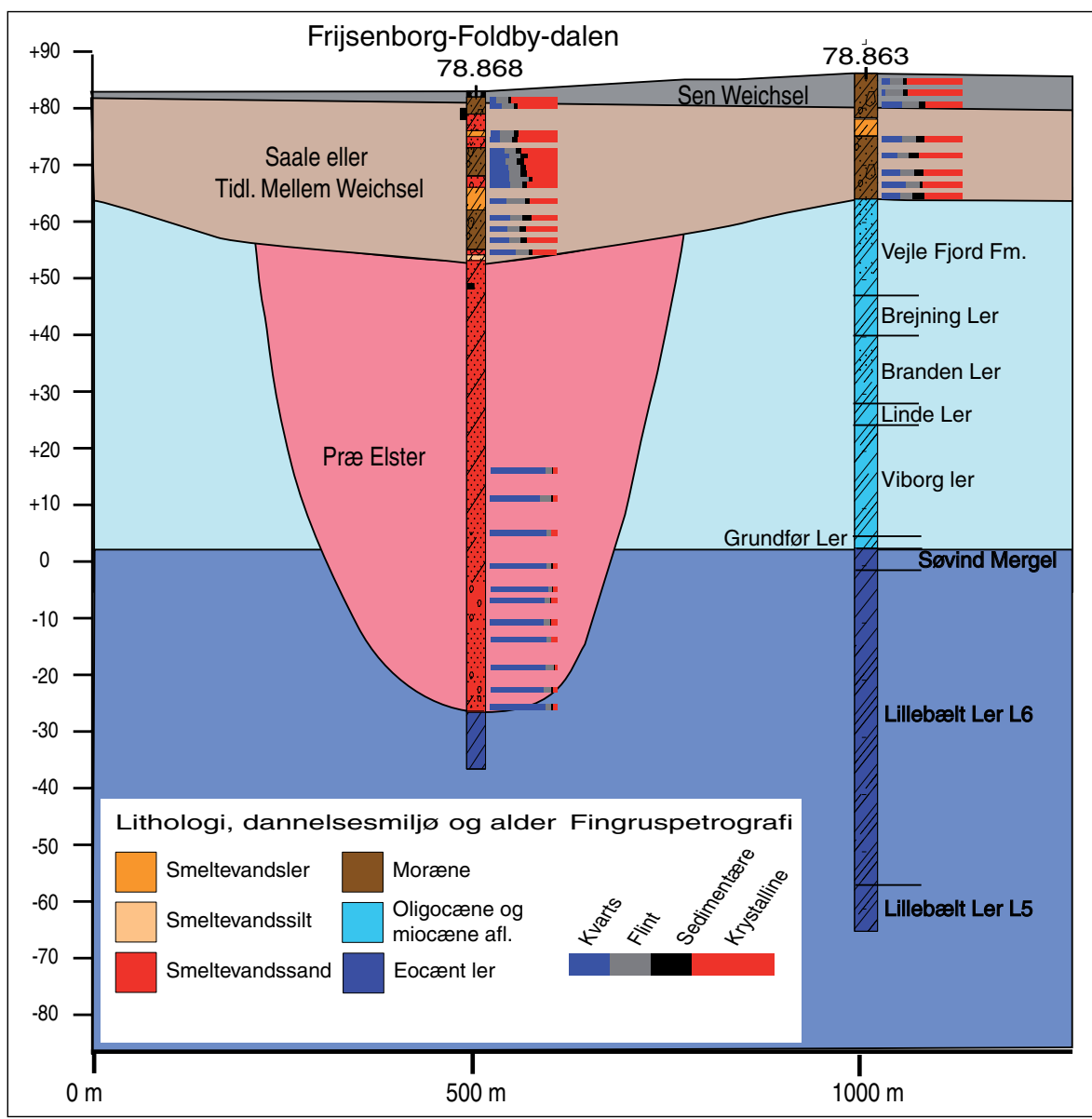

Geologisk snit på tvcers af Frijsenborg-Foldby-dalen. (Grafik: Jette Sørensen)

borg-Foldby-dalen, men erosionen har ikke været så dyb, at Præ Elster sedimenterne helt er fjernet her. I både FrijsenborgFoldby-dalen (boring 78.862) og i LilleFrijsenborg-dalen (boring 78.910) ses der i det nedre dalfyld enheder af moræneler, hvilket tyder på, at der i hvert fald periodisk har været kontakt mellem is og dalbund $i$ disse dale. Bemærk i øvrigt, at moræneleret og de tilhørende smeltevandsaflejringer $i$ Frijsenborg-Foldby-dalen har en identisk fingrussammensætning, hvilket som tidligere nævnt oftest er tilfældet. Dette forhold gør det muligt at korrelere de sandede og grusede smeltevandssedimenter, der udgør grundvandsmagasinerne i området.

Over dalindfyldningen i både Frijsenborg-Foldby-dalen og Lille Frijsenborg-dalen ses de moderat kvartsholdige aflejringer fra Saale og Tidlig Mellem Weichsel, og herover de meget kvartsfattige aflejringer fra Sen Weichsel.

\section{Flintrige sedimenter}

Stikprøverne fra boringer i Lille Frijsenborg-dalen (78.909 og 78.910) viser, at indfyldningen er helt forskellig fra indfyldningen i Frijsenborg-Foldby-dalen, idet flintindholdet er meget højt. I boring 78.910 fra krydspunktet mellem de to dale kan det ses, at de flintrige aflejringer overlejrer de kvartsrige Præ Elster-sedimenter, og de må således være yngre end dette. De overlej- res desuden af de sedimenter, der tolkes til at være afsat i Saale eller Tidlig Mellem Weichsel og må derfor aldersmæssigt indplaceres i Elster eller Saale. De flintrige aflejringer er ikke fundet på daglokaliteter i Århus, og deres alder kan derfor ikke afgøres nærmere.

I en nyere boring (dgu nr. 78.1023), der er placeret $i$ den vestligste del af Frijsenborg-Foldby-dalen (se figuren s.16 i forrige artikel), er der i den nedre del af lagserien fundet meget flintrige sedimenter, hvilket tyder på, at de disse aflejringer her udfylder det meste af dalen. I denne del af dalen ses desuden øverst en øvre, tyk lagserie af finkornede smeltevandssedimenter, der formodentligt er afsat i en issø. Præ Elstersedimenterne ses ikke i dalen her og er formodentligt eroderet bort.

\section{Oversigt over indfyldninger i dalene}

I figuren på sidste side er forløbet af de begravede dale i Århus Nord og ved Hadsten samt alderen af deres indfyldning skitseret. Den overvejende del af Frijsenborg-Foldbydalen er markeret med en lys rød farve, der markerer, at denne del af dalen er udfyldt med Præ Elster-sedimenter. Lille Frijsenborg-dalen er optegnet med grøn farve for at markere, at indfyldningen her aldersmæssigt er fra Elster eller Saale, mens de to store dale, der omkranser den nordøstlige, østlige og sydøstlige del af plateauet, er optegnet 
med en lysebrun farve for at markere, at disse dales indfyldning kan henføres til Saale eller Tidlig Mellem Weichsel. Indfyldningen i de dale, der er markeret med gråt, er endnu ikke undersøgt.

\section{Diskussion og konklusion}

I de to artikler om Århus Nord og Hadsten har vi illustreret, hvordan det ved hjælp af TEM-metoden har været muligt at kortlægge et helt system af begravede dale. Endvidere har vi set, hvordan det på baggrund af fingrusanalyser på prøver fra dybe undersøgelsesboringer i de begravede dale, har været muligt, at udrede relationerne mellem de forskellige dales indfyldning. Desuden har vi kunnet foretage en korrelation til områdets velunderbyggede stratigrafi og dermed vist, at de undersøgte dale, der omgiver Frijsenborg-Foldby-plateauet er blevet fyldt op under Saale eller Tidlig Mellem Weichsel, mens den ene af de dale, der gennemskærer plateauet, har en indfyldning, som kan henføres til et Præ Elster-isfremstød, formentlig Menap.

Jørgensen og Sandersen (2006) /3/ tolker, at de begravede dale i Danmark er dannet ved subglacial smeltevandserosion under gentagne isfremstød, selvom også direkte glacial erosion kan have spillet en mindre rolle. De beskæftiger sig bl.a. med de forskellige generationer af dale ved Århus Nord og konkluderer på baggrund af de geofysiske undersøgelser og på baggrund af boringsoplysninger, at der ses mindst tre generationer af dale.

Den ældste generation af dale har en sydøstlig til nordvestlig orientering, mens en formodentlig yngre generation er orienteret nord-syd, og den yngste generation er orienteret nordøst-sydvest. Blandt de ældste dale henregnes Frijsenborg-Foldby-dalen og Haar-Trige-Elsted-dalen, mens LilleFrijsenborg-dalen, der henregnes til den lidt yngre generation af dale, tilsyneladende skæres af de yngste dale i området, der bl.a. er repræsenteret af Ristrup-Grundfør-Ødumdalen.

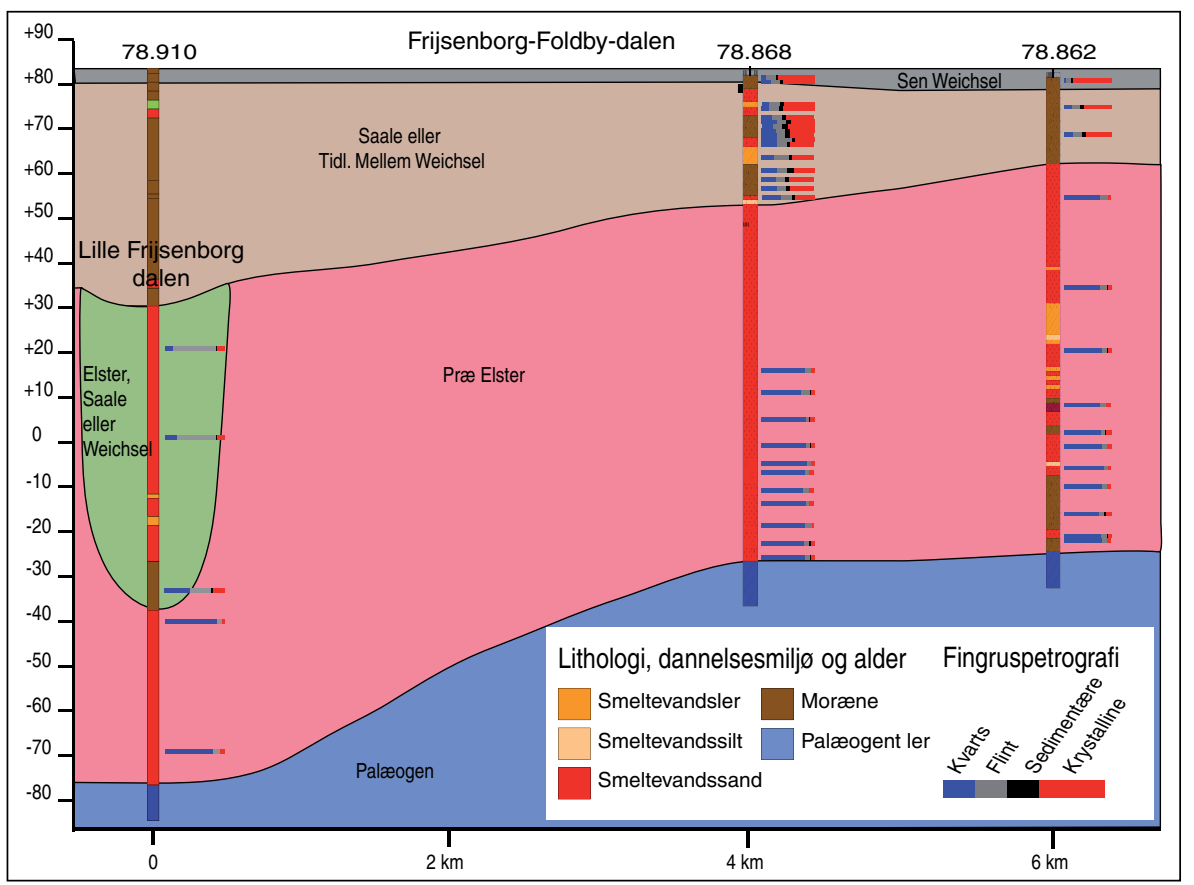

Geologisk snit på langs af Frijsenborg-Foldby-dalen. (Grafik: Jette Sørensen)

At Frijsenborg-Foldby-dalen og HaarTrige-Elsted-dalen skulle tilhøre samme gamle generation af tunneldale kan synes paradoksalt, da indfyldningen i FrijsenborgFoldby-dalen er af Præ Elster alder, mens indfyldningen i den anden dal er af Saale eller Tidlig Mellem Weichsel alder. Det er dog ikke sådan, at en dal nødvendigvis har samme alder som sin indfyldning, nok snarere tværtimod, idet dalsystemerne tilsyneladende har været genbrugt adskillige gange under de efterfølgende istider. Dette fremfører Jørgensen og Sandersen (2006) /3/, der i mange af dalene ser erosionsstrukturer, og om dette konstaterer, at de eksisterende dale ofte er blevet genbrugt, specielt hvis isen bevægede sig parallelt med dalens retning.

Haar-Trige-Elsted-dalen kan derfor også udmærket være dannet i et Præ Elsterisfremstød, men blot genbrugt adskillige gange siden. Dalens bredde varierer mellem
900 og $2.500 \mathrm{~m}$, og stedvist ses flanken udviklet som en slags terrasser, mens Frijsenborg-Foldby-dalen dels har meget stejle dalflanker og dels en begrænset bredde, der blot veksler mellem 400 og $1.000 \mathrm{~m}$. Dette har ledt til overvejelser om, hvorvidt dalenes bredde kan være udtryk for, hvor meget de har været genbrugt under efterfølgende glaciationer. Er det sådan, at jo bredere dalene er, og jo lavere hældning deres flanker har, jo flere erosionsbegivenheder har de været udsat for? Tanken er i det mindste nærliggende.

Det er i øvrigt påfaldende, at Frijsenborg-Foldby-dalen forløber langs det prækvartære plateaus absolutte højderyg, hvor der tilsyneladende har været mindst erosion. Plateauet er tydeligvis eroderet ned til lavere niveauer ud mod randen, der hvor de bredere begravede dale med et yngre indhold af sedimenter findes. Smeltevandet vil søge 
den vej, der frembyder mindst modstand, og vandet har åbenbart nemmere kunnet bortdræne i de dalsystemer, der omkranser plateauet.

Det er i øvrigt en fascinerende tanke, at vandet fra dette fremtidige grundvandsmagasin vil strømme gennem aflejringer fra én af de ældste istider, der kendes her i landet.

\section{Referenceliste}

11/ Sørensen, J., Kronborg, C., Nielsen, O.B., Kragelund, A., 2004: Århus Amt, Arhus Nord. Fase 2, petrografisk korrelation af 9 boringer fra Århus Nord. Afd. for Sediment-Geologi, Geologisk Institut, Aarhus Universitet.

/2/ Kronborg, C., Bender, H., Bjerre, R., Friborg, R., Jakobsen, H.O., Kristiansen, L., Rasmussen, P., Sørensen, P.R., og Larsen., G.: 1990: Glacial stratigraphy of East and Central Jutland. Boreas, 19, p. 273-287. /3/ Jørgensen, F og Sandersen, P, 2006:

Buried and open tunnel valleys in Denmark - erosion beneath multiple ice sheets. Quaternary Science Reviews, 25, p. 1339-1363. Tak til Helle Clausen fra Sedimentsamarbejdet for omhyggelig korrekturlcesning af artiklen og forslag til sproglige forbedringer

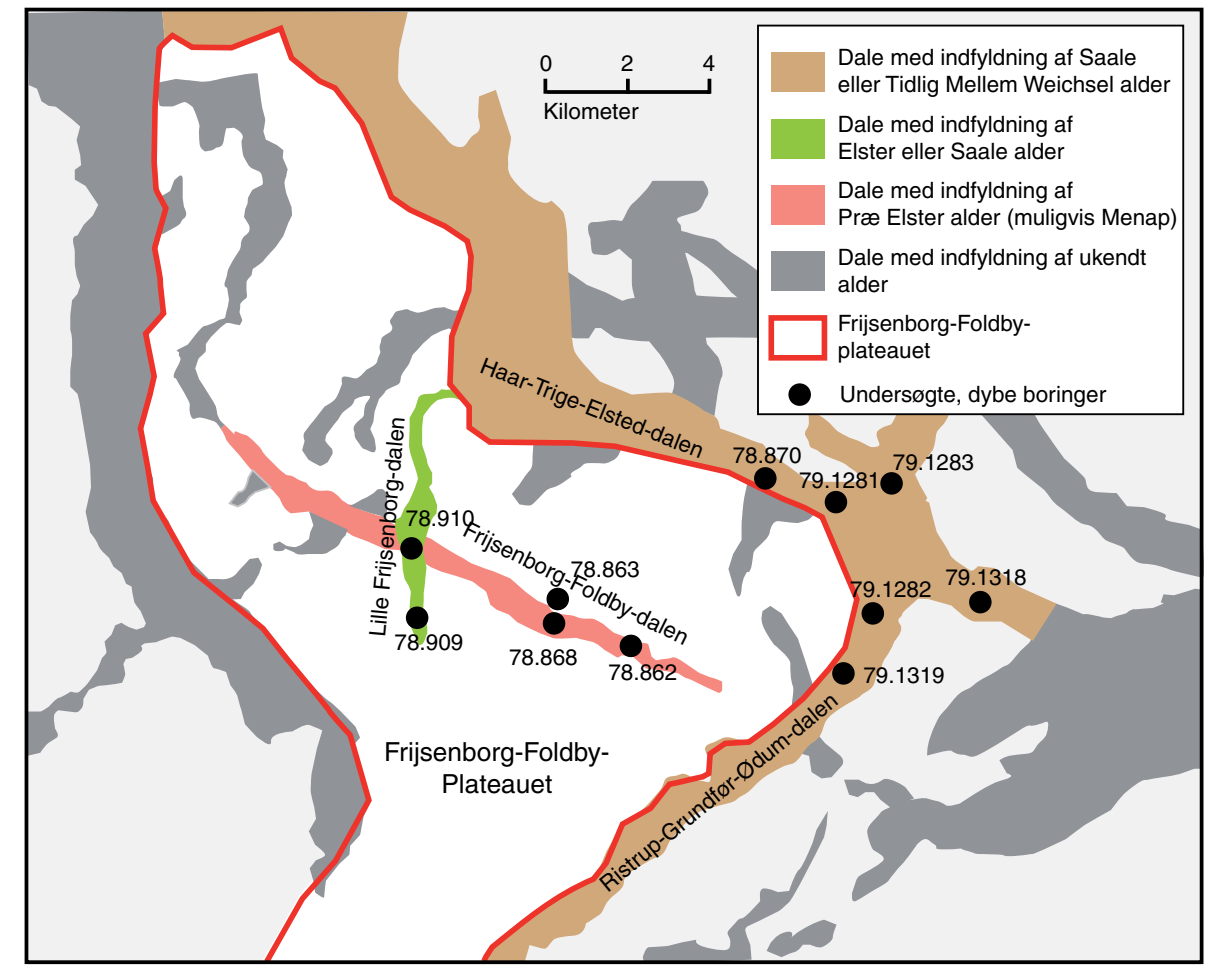

Oversigt over de begravede dale og det undersøgte Frijsenborg-Foldby-plateau i Århus Nord og ved Hadsten. De forskellige aldre på dalenes indfyldning er markeret med forskellig farve. (Grafik:Jette Sørensen) 